\title{
Spontaneously producing syngas from MFC-MEC coupling system based on biocompatible bifunctional metal-free electrocatalyst
}

\author{
Wei Wang ${ }^{1,2}$, Rahul Anil Borse ${ }^{1,2}$, Jiafang Xie ${ }^{1}$ and Yaobing Wang ${ }^{1,3^{*}}$
}

\begin{abstract}
The preparation of high-value fuels and chemicals through the electrochemical carbon dioxide reduction reaction (CDRR) is of great significance to the virtuous cycle of carbon dioxide. However, due to the high overpotential involved in this reaction, high power consumption and highcost noble-metal-based catalysts are required for driving this process. Herein, the electrochemical CDRR was achieved on biocompatible metal-free nitrogen, phosphorus co-doped carbon-based materials (NP-C) in the microbial fuel cellmicrobial electrolysis cell (MFC-MEC) coupling system. As the bioelectrochemistry in MFC supplied power to drive the electrocatalysis in MEC, syngas was spontaneously produced from this coupling system without external energy input. With the NP-C materials as the excellent bifunctional electrocatalyst for the CDRR and oxygen reduction reaction (ORR), the current density of the MEC reached $-0.52 \mathrm{~mA} \mathrm{~cm}^{-2}$, and the Faradaic efficiencies (FEs) of $\mathrm{CO}$ and $\mathrm{H}_{2}$ were $60 \%$ and $40 \%$, respectively, at a load resistance of $10 \Omega$. Moreover, the $\mathrm{CO} / \mathrm{H}_{2}$ product ratio can be changed by adjusting the load resistance, which will widely meet various demand of syngas usage in further reactions. This study provides a spontaneous and tunable production of syngas in biogas digesters via a electrochemical strategy.
\end{abstract}

Keywords: spontaneous production, syngas, MFC-MEC coupling system, N/P-co-doped carbon electrocatalyst

\section{INTRODUCTION}

Excessive emissions of carbon dioxide $\left(\mathrm{CO}_{2}\right)$ have caused some serious environmental problems due to the massive burning of fossil fuels, which seriously endangers human sustainable development $[1,2]$. The preparation of highvalue fuels and chemicals by electrochemical reduction reactions of $\mathrm{CO}_{2}$ may be one of the promising ways to solve this problem [3]. Among them, the electrochemical reduction of $\mathrm{CO}_{2}$ to produce syngas has attracted widespread attention. Because the syngas currently used in industry mainly comes from coal vaporization and natural gas steam conversion, its energy consumption and cost are relatively high [4-7]. Electrocatalytic reduction of $\mathrm{CO}_{2}$ may become another promising syngas preparation technology. However, due to the high overpotential in this reaction, high power consumption and high-cost noble-metal-based catalysts are required for driving this process. In order to avoid the loss of energy caused by power generation, other clean energy sources (such as solar and wind) are considered to be the most feasible method for power generation. For example, Ghausi et al. [8] used a solar cell coupled with a $\mathrm{CO}_{2}$ electrolysis cell to catalyze $\mathrm{CO}_{2}$ reduction. As a self-powered device, the microbial fuel cell-microbial electrolysis cell (MFC-MEC) coupling system can react spontaneously without an external power source. This method provides the possibility to solve the problem of the source of electrical energy in electrocatalytic $\mathrm{CO}_{2}$ reduction. The system has been used for hydrogen production in the hydrogen production reaction (HER), as well as for wastewater treatment in the absence of an external power source [9-12]. In addition, Zhao et al. [13] reported for the first time the storage and conversion of $\mathrm{CO}_{2}$ using the MFC-MEC coupling system.

\footnotetext{
${ }^{1}$ Key Laboratory of Design and Assembly of Functional Nanostructures, Fujian Provincial Key Laboratory of Nanomaterials, State Key Laboratory of Structural Chemistry, Key Laboratory of Optoelectronic Materials Chemistry and Physics, Fujian Institute of Research on the Structure of Matter, Chinese Academy of Sciences, Fuzhou 350002, China

${ }^{2}$ University of Chinese Academy of Sciences, Beijing 100049, China

${ }^{3}$ Dalian National Laboratory for Clean Energy, Dalian 116023, China

* Corresponding author (email: wangyb@fjirsm.ac.cn)
} 
The composite material of multiwall carbon nanotube (MWCNT) and CoTAPc was used as the MEC cathode to catalyze the reduction of $\mathrm{CO}_{2}$ to formic acid. However, formic acid was a liquid product that was easy to produce but difficult to separate from the system. On this basis, we further studied the use of biocompatible metal-free carbon-based catalysts to spontaneously produce syngas in the MFC-MEC coupling system.

Recently, carbon-based materials have been widely used as an electrode due to their good electrical conductivity, high specific surface area, relatively low cost, and environmental friendliness $[14,15]$. When heteroatoms were incorporated into carbon materials, their physical and chemical properties can be significantly adjusted, which may promote their catalytic function [16]. In recent years, nitrogen-doped carbon-based materials, such as $\mathrm{N}$-doped graphene [17], mesoporous carbon [18], nanodiamond [19], carbon nanofibers [20] and CNTs [21] have shown good electrocatalytic properties for the carbon dioxide reduction reaction (CDRR), even comparable to precious metal catalysts. In addition, other heteroatom-doped ( $\mathrm{P}$, $\mathrm{F}$, and $\mathrm{Si}$ ) carbon-based materials have also been developed recently $[8,22,23]$. Meanwhile, for MFCs, the cathode was one of the important compositions that determine the ultimate generated electrical energy. Oxygen $\left(\mathrm{O}_{2}\right)$ is considered as the ideal electron acceptor toward the cathodic reaction in MFC because of its high content in the air. However, due to the sluggish rate of oxygen reduction reaction (ORR), a catalyst is necessary $[24,25]$. Generally, in ORR, the Pt-based catalyst has been extensively used in the MFC system [26,27], but high cost and relatively poor stability hinder its practical application. In order to solve this problem, the heteroatomdoped carbon as a potential candidate for replacing Ptbased catalyst has been greatly developed in the ORR [2839]. Therefore, suitable metal-free carbon materials with catalytic activity for both ORR and CDRR in the MFCMEC coupling system can efficiently electrochemically produce syngas.

In this study, a biocompatible metal-free N/P-co-doped carbon material (NP-C) was synthesized via a facile pyrolysis of cellulose mixed with urea and phytic acid as nitrogen and phosphorus source, respectively, as an effective bifunctional electrocatalyst for CDRR and ORR in the MFC-MEC coupling system. The combination of the bioelectrochemical process and a catalytic electrode has boosted the spontaneous production of syngas without external energy input.

\section{EXPERIMENTAL SECTION}

\section{Chemicals and reagents}

Carbon paper (HCP 020N, HeSen), Nafion membrane (Nafion 211, DuPont), Nafion membrane solution (20\%, DuPont), $\mathrm{KHCO}_{3}$ (99.7\%, Sigma-Aldrich), phytic acid solution $\left(50 \%\right.$ in $\mathrm{H}_{2} \mathrm{O}$, Aladdin), $\alpha$-cellulose $(50 \mu \mathrm{m}$, Aladdin), and deionized (DI) water were used as received. All other reagents were purchased from Sinopharm Chemical Reagent Co., Ltd. without further purification.

\section{Synthesis of NP-C}

The nitrogen-phosphorus co-doped carbon materials were synthesized by the pyrolysis of microcrystalline cellulose $(50 \mu \mathrm{m})$, urea, and phytic acid. Typically, the mixture of cellulose $(4 \mathrm{mmol})$, urea $(40 \mathrm{mmol})$ and phytic acid $(0.8 \mathrm{mmol})$ was transferred to the tube furnace, followed by annealing at $900^{\circ} \mathrm{C}\left(5^{\circ} \mathrm{C} \mathrm{min}{ }^{-1}\right)$ for $1 \mathrm{~h}$ under $\mathrm{Ar}$ atmosphere. After cooling down to $25^{\circ} \mathrm{C}, \mathrm{NP}-\mathrm{C}$ was obtained. As comparison, the P-C and N-C were also obtained in the same way without urea and phytic acid, respectively. Additionally, undoped carbon (C) was also obtained by pyrolyzing microcrystalline cellulose under the same conditions.

\section{Electrochemical measurements}

The electrochemical testing was performed with a threeelectrode system by an electrochemical workstation (CHI $660 \mathrm{E})$. Pt mesh $\left(1 \mathrm{~cm}^{2}\right)$ and $\mathrm{Ag} / \mathrm{AgCl}$ (saturated with $\mathrm{KCl}$ ) were used as counter and reference electrodes, respectively. For catalyst ink preparation, $10 \mathrm{mg}$ of the sample was dispersed in the mixture of $0.95 \mathrm{~mL}$ of isopropyl alcohol and $0.05 \mathrm{~mL}$ of $20 \%$ Nafion membrane solution with sonication. The suspension was dropped on the carbon paper $\left(0.1 \mathrm{~mL} \mathrm{~cm}^{-2}\right.$, catalyst loading mass: $1.0 \mathrm{mg} \mathrm{cm}^{-2}$ ) and dried at room temperature. The electrochemical CDRR was performed in an $\mathrm{H}$-type reactor filled with $0.1 \mathrm{~mol} \mathrm{~L}^{-1} \mathrm{KHCO}_{3}$ solution separated by a Nafion membrane. Prior to experiments, the catholyte was pumped with $\mathrm{CO}_{2}$ (purity of 99.999\%) for $30 \mathrm{~min}$, and $\mathrm{CO}_{2}$ was controlled at a rate of $20 \mathrm{~mL} \mathrm{~min}^{-1}$ during experiments. Electrochemical ORR test was conducted in $0.1 \mathrm{~mol} \mathrm{~L}^{-1}$ phosphate buffer solution (PBS: $10.9 \mathrm{~g} \mathrm{~L}^{-1}$ $\mathrm{Na}_{2} \mathrm{HPO}_{4} \cdot 12 \mathrm{H}_{2} \mathrm{O}, 3.04 \mathrm{~g} \mathrm{~L}^{-1} \mathrm{NaH}_{2} \mathrm{PO}_{4} \cdot 2 \mathrm{H}_{2} \mathrm{O}, 0.31 \mathrm{~g} \mathrm{~L}^{-1}$ $\mathrm{NH}_{4} \mathrm{Cl}$, and $0.13 \mathrm{~g} \mathrm{~L}^{-1} \mathrm{KCl}$ ) with the catalyst loaded on the rotating disk electrode (RDE) with the diameter of $5 \mathrm{~mm}$. Prior to experiments, the electrolyte was pumped with $\mathrm{O}_{2}$ (purity of $99.999 \%$ ) for $30 \mathrm{~min}$. During the experiment, $\mathrm{O}_{2}$ was continuously fed into the electrolyte at a constant flow rate. The potential measured with reference 
electrode was converted to RHE scale with the equation $E_{\mathrm{RHE}}=E_{\mathrm{Ag} / \mathrm{AgCl}}+0.197 \mathrm{~V}+(0.0591 \times \mathrm{pH}) \mathrm{V}$.

\section{Reactor construction}

The coupling system consisted of an H-type MEC for implementing electrochemical CDRR and a singlechamber MFC (4 cm in length and $3 \mathrm{~cm}$ in diameter) for producing electric power. The anodes of MFC and MEC were graphite fiber brushes $(3 \mathrm{~cm}$ long, $3 \mathrm{~cm}$ outer diameter), which were soaked in acetone overnight, and then heated at $450^{\circ} \mathrm{C}$ for $30 \mathrm{~min}$. The catalyst-coated carbon paper $\left(1 \mathrm{mg} \mathrm{cm}^{-2}\right)$ was used as the cathodes of MEC and MFC, the surface area of which were $2 \mathrm{~cm}^{2}$ and $7 \mathrm{~cm}^{2}$, respectively. Each MFC was operated at $30 \pm 1{ }^{\circ} \mathrm{C}$ and fed with a medium containing acetate $\left(1.5 \mathrm{~g} \mathrm{~L}^{-1}\right)$ in $50 \mathrm{mmol} \mathrm{L}^{-1}$ PBS.

\section{Gas detection and the Faradaic efficiencies (FEs) of gas products}

The gas products produced during the CDRR were detected using a gas chromatograph (GC, 9700II, FULI). Calculation of the FEs for $\mathrm{CO}$ and $\mathrm{H}_{2}$ at a given potential or current was based on the following equations:

$$
\begin{aligned}
& \mathrm{FE}_{\mathrm{CO}}=\frac{i_{\mathrm{CO}}}{i_{\text {total }}}=\frac{X_{\mathrm{CO}} \times v_{\mathrm{CO}} \times n \times 96485}{i_{\text {total }}}, \\
& \mathrm{FE}_{\mathrm{H}_{2}}=\frac{i_{\mathrm{H}_{2}}}{i_{\text {total }}}=\frac{X_{\mathrm{H}_{2}} \times v_{\mathrm{CO}_{2}} \times n \times 96485}{i_{\text {total }}},
\end{aligned}
$$

where $i_{\mathrm{CO}}$ (and $i_{\mathrm{H}_{2}}$ ) is the partial current for $\mathrm{CO}\left(\right.$ and $\mathrm{H}_{2}$ ) production, $i_{\text {total }}$ is the total current, $X_{\mathrm{CO}}\left(X_{\mathrm{H}_{2}}\right)$ is the production rate of $\mathrm{CO}$ (and $\mathrm{H}_{2}$ ) (measured by GC), $v_{\mathrm{CO}_{2}}$ is the flow rate of $\mathrm{CO}_{2}$, and $n$ is the number of electrons transferred for each product molecule formation (it is 2 for both $\mathrm{CO}$ and $\mathrm{H}_{2}$ ).

\section{Characterization}

Powder X-ray diffraction (XRD) profiles were collected on a MiniFlex $600 \mathrm{X}$-ray diffractometer at the scan rate of $3^{\circ} \mathrm{min}^{-1}$ ( $\mathrm{Cu}$ Ka source). High-resolution scanning electron microscopy (SEM) image was obtained using a JEOL-6700F and low-resolution SEM images by using Phenon G2 Scan Electron Microscopy. Transmission electron microscope (TEM, JEOL JEM-2010) equipped with an energy dispersive X-ray detector (EDX) was applied for the morphologies and elemental contents of the as-prepared catalysts. Nitrogen adsorption-desorption isotherms were determined using automatic volumetric adsorption equipment (Autosorb-iQ, Quantachrome). The specific surface areas for the samples were figured by the Brunner-Emmet-Teller (BET) method, and the pore size distributions for the samples were figured from an adsorption branch of the isotherm by the Barrett-JoynerHalenda (BJH) model. The surface valence state of the samples was analyzed by X-ray photoelectron spectroscopy (XPS) with a VG ESCALAB 250. Raman spectra were obtained from a Raman spectrometer (LabRAM $\mathrm{HR}$ ) using a $532 \mathrm{~nm}$ laser.

\section{RESULTS AND DISCUSSION}

\section{Synthesis and characterization of NP-C}

The NP-C materials were synthesized by pyrolyzing cellulose in the presence of urea and phytic acid. For comparison, nitrogen-doped carbon (N-C) and phosphorusdoped carbon (P-C) with corresponding single doping and undoped carbon (C) were also synthesized. SEM (Fig. 1a) and TEM (Fig. 1b) images show the crumpled and sheet-like morphology for the prepared NP-C sample. In contrast, N-C (Fig. S1d) and pure C (Fig. S1b) reveal a rod-like structure consistent with the structure of the raw material cellulose (Fig. S1a), while P-C displays a broken block morphology (Fig. S1c). Moreover, the corresponding elemental mapping (Fig. 1c), verifies the uniform dispersion of carbon, nitrogen, and phosphorus in NP-C. The EDX analysis further confirms the existence of carbon, phosphorus, nitrogen, and oxygen in NP-C (Fig. S2). The $\mathrm{N}_{2}$ adsorption-desorption isotherm (Fig. S3) displays a high specific surface area of $1124 \mathrm{~m}^{2} \mathrm{~g}^{-1}$ for NP-C. P-C (Fig. S4), N-C (Fig. S5) and pure C (Fig. S6) also show high specific surface areas $\left(1638,667\right.$, and $1021 \mathrm{~m}^{2} \mathrm{~g}^{-1}$, respectively). The surface area expansion resulting from the P doping (Figs S3-S6) has positive effects on the CDRR activity on NP-C. The XRD patterns (Fig. S7) of NP-C, P-C, N-C and pure C all show a typical peak at $2 \theta=24^{\circ}$ that can be readily assigned to graphitic carbon (002), consistent with the appearance of the $\mathrm{G}$ band (ca. $1600 \mathrm{~cm}^{-1}$ ) in the Raman spectra (Fig. S8). The D band at about $1360 \mathrm{~cm}^{-1}$ and the higher intensity of $\mathrm{G}$ band imply the enriched defects and graphite carbon in NP-C. The XPS spectrum in Fig. 1d shows that NP-C, N-C, P-C and pure C all contain the main elements of $\mathrm{C}$ and $\mathrm{O}$, but only NP-C contains both $\mathrm{N}(5.4 \%)$ and $\mathrm{P}(2.16 \%)$ atoms, evidencing the formation of $\mathrm{N}$ and $\mathrm{P}$ co-doping in NP-C. Moreover, the high-resolution XPS spectra for C 1s (Fig. S9), N 1s (Fig. 1e), and P 2p (Fig. 1f) in NP-C suggest the existence of $\mathrm{C}-\mathrm{N}$ and $\mathrm{C}-\mathrm{P}$ bonds. Therefore, the prepared NP-C has a codoping of $\mathrm{N}$ and $\mathrm{P}$, and a high specific surface area, which may play an active role in electrolysis. 

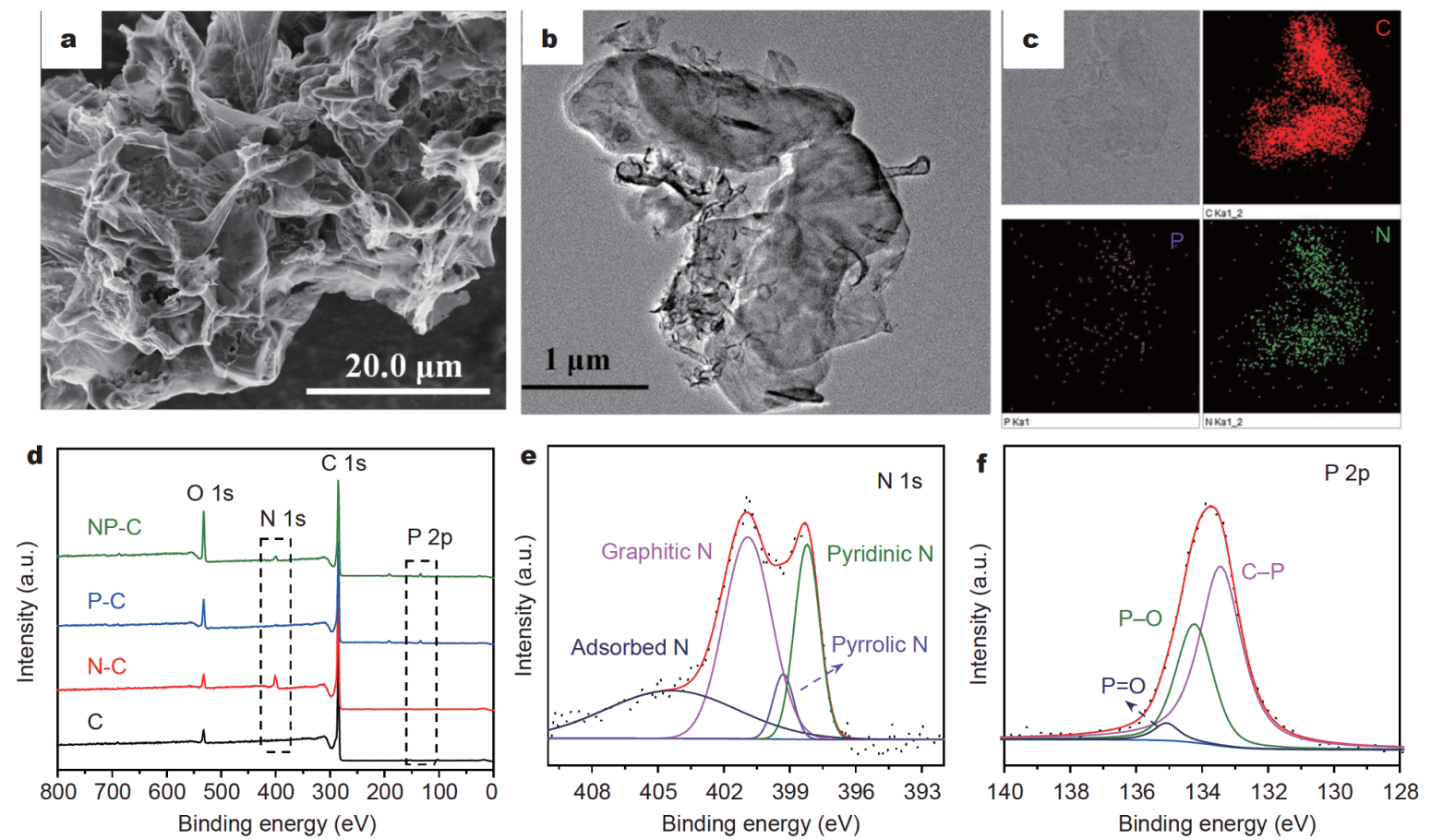

Figure 1 (a) SEM image, (b) typical TEM image, and (c) elemental mapping images of NP-C. (d) Survey XPS spectra of cellulose doped carbon NPC, P-C, N-C and pure C. (e, f) High-resolution XPS spectra of NP-C: (e) N 1s, and (f) P 2p.

\section{CDRR and ORR performance of NP-C}

The electrocatalytic performance of NP-C in CDRR and ORR were first tested by linear sweep voltammetry (LSV). Fig. 2a displays the LSV curves of CDRR with a scan rate of $10 \mathrm{mV} \mathrm{s}^{-1}$, in which NP-C has a current density of 1.73 and $1.08 \mathrm{~mA} \mathrm{~cm}^{-2}$ at $-0.59 \mathrm{~V}$ in $\mathrm{CO}_{2}$ and $\mathrm{Ar}$, respectively. The large current density gap between $\mathrm{CO}_{2}$ and Ar suggests the high electrocatalytic activity for CDRR on NP-C. When further compared with N-C, P-C and pure C, NP$\mathrm{C}$ has a larger gap, indicating that NP-C has a better inhibition of competitive HER. In the further potentiostatic electrolysis of $\mathrm{CO}_{2}$, NP-C displays a much higher partial current density for $\mathrm{CO}_{2}$-to-CO conversion $\left(j_{\mathrm{CO}}\right)$ than $\mathrm{P}-\mathrm{C}, \mathrm{N}-\mathrm{C}$, pure $\mathrm{C}$ and even their sum at potentials ranging from -0.4 to $-0.9 \mathrm{~V}$ (Fig. $2 \mathrm{~b}$ ), demonstrating the best electrocatalytic CDRR performance of the co-doped $\mathrm{NP}-\mathrm{C}$. The maximum $\mathrm{FE}_{\mathrm{CO}}$ of NP-C is $81 \%$ at $-0.59 \mathrm{~V} v s$. RHE with $j_{\mathrm{CO}}$ reaching $1.3 \mathrm{~mA} \mathrm{~cm}{ }^{-2}$, matching the reported advanced metal-free carbon-based catalysts (Table S1), which allows further application of NP-C in our dsigned device. When competitive HER was also accounted, a selectivity map could be obtained by plotting FEs for $\mathrm{CO}$ and $\mathrm{H}_{2}$, as shown in Fig. $2 \mathrm{c}$ and Fig. S10. Compared with $\mathrm{P}-\mathrm{C}, \mathrm{N}-\mathrm{C}$, and pure $\mathrm{C}$, the $\mathrm{FE}$ of the competitive HER was well suppressed on NP-C. In order to further study the intrinsic reasons for the enhancement of CDRR performance by nitrogen and phosphorus codoping, Tafel plots of $\mathrm{CO}$ generation were first conducted. NP-C presented the lowest Tafel slope $\left(122.6 \mathrm{mV} \mathrm{dec}^{-1}\right.$, Fig. 2d), which was much lower than that of C $\left(224.2 \mathrm{mV} \mathrm{dec}^{-1}\right), \mathrm{N}-\mathrm{C}\left(273.8 \mathrm{mV} \mathrm{dec}^{-1}\right)$ and P$\mathrm{C}\left(163.2 \mathrm{mV} \mathrm{dec}^{-1}\right)$, suggesting the fastest kinetics of NPC. Additionally, the electrochemical active surface area (ECSA) was evaluated by measuring the double-layer capacitance $\left(C_{\mathrm{dl}}\right)$, which was derived from the cyclic voltammogram $(\mathrm{CV})$ at a series of scan rates. Although NP-C shows a lower ECSA than P-C (Fig. S11), it still display the highest ECSA-normalized current density (Table S2), suggesting the active sites on NP-C have a higher intrinsic activity to CDRR than that on the singledoped N-C and P-C, which could partially explain the superior CDRR on NP-C than that on the single-doped $\mathrm{P}-\mathrm{C}$ and $\mathrm{N}-\mathrm{C}$ as well as undoped $\mathrm{C}$. The higher intrinsic activity of active sites on NP-C might be derived from the co-doping of $\mathrm{N}$ and $\mathrm{P}$ hetero-atoms, which was in agreement with the previous reports [40-42]. Because the active site and mechanism were very similar to previous studies [42], the focus of this study was the feasibility of the device, and there was no further in-depth study of the mechanism. Moreover, the low ECSA of N-C can par- 

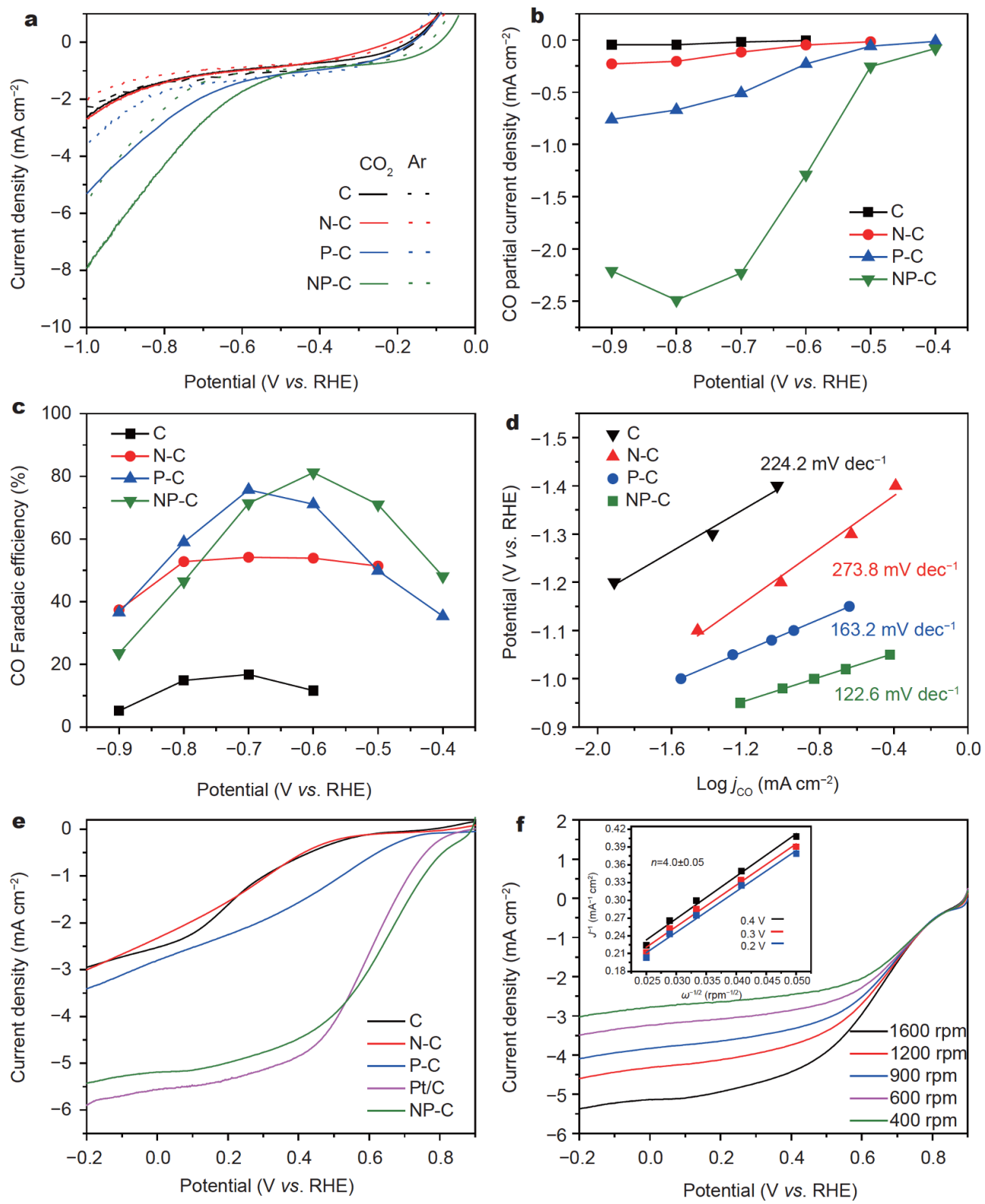

Figure 2 Electrochemical tests of CDRR and ORR $n$ on NP-C, P-C, N-C and pure C catalysts in neutral solution. (a) LSV curves in 0.1 mol $\mathrm{L}^{-1}$ $\mathrm{KHCO}_{3}$ saturated with $\mathrm{CO}_{2}$ and Ar. Scan rate: $10 \mathrm{mV} \mathrm{s}^{-1}$. (b) The partial current density of $\mathrm{CO}\left(j_{\mathrm{CO}}\right)$ and (c) FE $\mathrm{CO}$ by potentiostatic electrolysis at several applied potentials. (d) Tafel slope of the CDRR. (e) ORR LSV curves of NP-C, Pt/C, P-C, N-C and pure C in 0.1 mol L ${ }^{-1} \mathrm{PBS}$ saturated with $\mathrm{O}_{2}$. Scan rate: $50 \mathrm{mV} \mathrm{s}^{-1}$. (f) LSV curves of NP-C at different speeds (inset: K-L diagram of NP-C at $0.2,0.3$ and $0.4 \mathrm{~V}$ ).

tially explain its poor performance compared with the reported nitrogen-doped carbon-based materials $[40,43]$. After 10-h continuous electrolysis, the CDRR retained half of the initial current density while the $\mathrm{FE}_{\mathrm{CO}}$ decayed by $20 \%$ (Fig. S12), possibly due to the loss of active sites on NP-C. Therefore, NP-C has higher activity and stability of CDRR, and can be an advanced metal-free carbon-based electrocatalyst.
The LSV of the ORR was measured at $1600 \mathrm{rpm}$ on a $\mathrm{RDE}$ in the $\mathrm{O}_{2}$-saturated $0.1 \mathrm{~mol} \mathrm{~L}^{-1} \mathrm{PBS}$ solution to study the ORR performance. As shown in Fig. 2e, the initial potential of NP-C was $0.84 \mathrm{~V}$, which was comparable to commercial $\mathrm{Pt} / \mathrm{C}(0.85 \mathrm{~V})$, and significantly higher than that of P-C $(0.76 \mathrm{~V}), \mathrm{N}-\mathrm{C}(0.61 \mathrm{~V})$ and pure C $(0.64 \mathrm{~V})$. The Koutecky-Levich (K-L) plots of NP-C (Fig. 2f) exhibited good linearity with a mean electron 
transfer number $(n)$ of 4.0 , indicating that the ORR on $\mathrm{NP}-\mathrm{C}$ was close to the four-electron transfer process. As a comparison, the K-L plots of Pt/C (Fig. S13), P-C (Fig. S14), N-C (Fig. S15) and pure C (Fig. S16) were also measured and displayed lower or comparable $n$ of 3.9, 3.8, 3.6 and 3.7, respectively. The above results suggest that the NP-C catalyst exhibits higher electrocatalytic ORR performance than the $\mathrm{P}-\mathrm{C}, \mathrm{N}-\mathrm{C}$ and pure $\mathrm{C}$ catalysts and it is comparable to the commercial $\mathrm{Pt} / \mathrm{C}$ catalyst. The higher ORR electrocatalytic activity of the co-doped NP$\mathrm{C}$ catalyst than that of the single-doped P-C and N-C could be ascribed to the synergic effect of the $\mathrm{N}$ and $\mathrm{P}$ doping, which is consistent with the reported literatures [44-46]. Therefore, NP-C is an excellent dual-functional electrocatalyst for the CDRR/ORR, which can well meet the catalyst requirements of the MFC-MEC coupling system.

\section{MFC testing}

The single-chamber MFC was tested under optimal conditions using NP-C as the air-cathode catalyst (Fig. S17). After one week of incubation and adaptation, a stable and repeatable peak voltage of $0.650 \mathrm{~V}$ for MFC (cathode potential of $0.195 \mathrm{~V}$ and anode potential of $-0.455 \mathrm{~V}$ ) was produced on a $1000 \Omega$ resistor, which lasted for $20 \mathrm{~h}$ in each cycle (Fig. S17). As shown in Fig. 3a, the anode potential in the MFC was kept at almost the same value under different resistances, and the cathode potential gradually became negative as the resistance decreased. Fig. $3 \mathrm{~b}$ show that the NP-C has an open circuit voltage of $790 \mathrm{mV}$ and a maximum power density of $2021 \mathrm{~mW} \mathrm{~m}^{-2}$. The polarization and power density curves indicate that MFC with NP-C as the cathode shows a high activity, comparable to those with the reported advanced metal-free carbon-based catalyst cathodes (Table S3).

\section{MFC-MEC coupling system testing}

Based on the successful operation of MFC with NP-C catalyst cathode, the MFC-MEC coupling system could be built by linking MEC and MFC with wire (Fig. S18). The syngas formation from the MFC-MEC coupling system was tested by adjusting the resistance. As shown in Fig. 4a, the circuit current density decreased as the load resistance increased. When the resistance increased from $10 \Omega$ to $2 \mathrm{k} \Omega$, the current density decreased from -0.21 to $-0.04 \mathrm{~mA} \mathrm{~cm}^{-2}$ and the cathode potential decreased from -0.366 to $-0.285 \mathrm{~V}$. Meanwhile, syngas production at different cathode potential was analyzed (Fig. 4b). When the load resistance was $10 \Omega$, the FEs of $\mathrm{CO}$ and $\mathrm{H}_{2}$ were $43 \%$ and $57 \%$, respectively. Moreover, as the load resistance increased, the $\mathrm{FE}_{\mathrm{CO}}$ decreased, while the $\mathrm{FE}_{\mathrm{H}_{2}}$ accounted for a higher proportion. Furthermore, another electrically assisted MFC unit was introduced in series in the coupling system to investigate the performance variation of the coupling system performance at increased electric power $[9,12]$. As shown in Fig. S19, at the loading resistance of $10 \Omega$, the current density at the cathode of the MEC reached $-0.52 \mathrm{~mA} \mathrm{~cm}^{-2}$, and the FEs of $\mathrm{CO}$ and $\mathrm{H}_{2}$ were $60 \%$ and $40 \%$, respectively. Similarly, as the loading resistance increased, the $\mathrm{FE}_{\mathrm{CO}}$ decreased and the $\mathrm{FE}_{\mathrm{H} 2}$ increased. Therefore, with NP-C as the biocompatible bifunctional electrocatalyst, we successfully built a novel MFC-MEC coupling system (Fig. S18) with tunable syngas product by adjusting the load resistance, and the $\mathrm{CO} / \mathrm{H}_{2}$ ratio in the syngas was suitable for the typical range of syngas ratios $\left(\mathrm{CO} / \mathrm{H}_{2}, 0.23-2.26\right)$ in a thermal catalytic reaction. This study provids a potential electrochemical strategy for the spontaneous production of syngas through microbial systems in biogas digesters, as
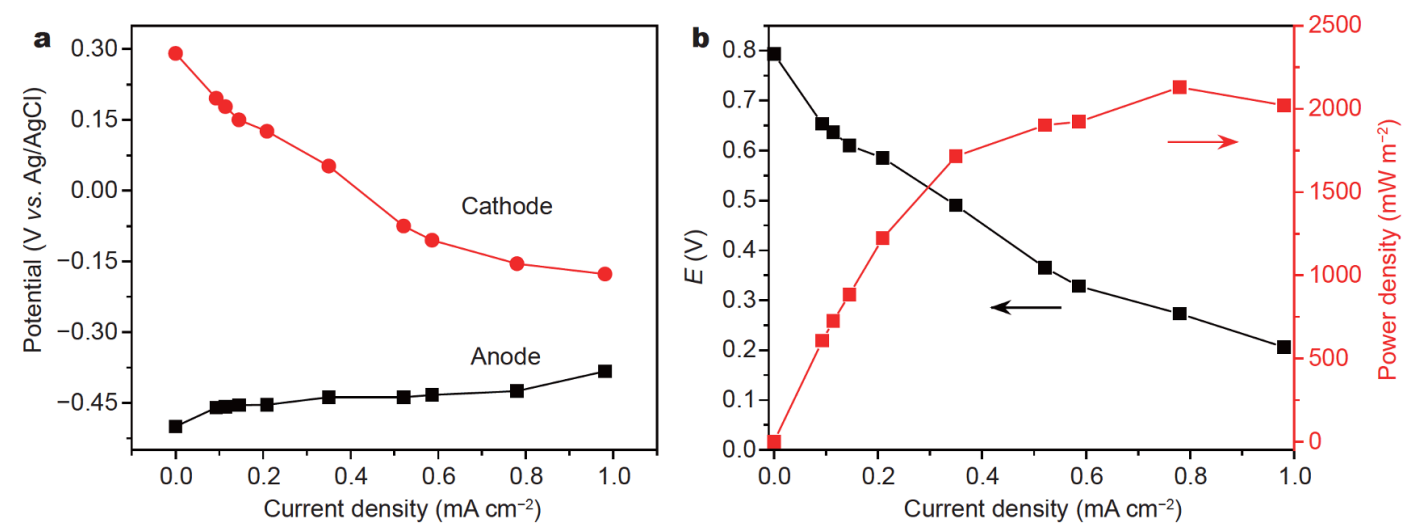

Figure 3 (a) Anode and cathode potentials of the MFC. (b) The polarization and power density curves of MFC using NP-C as the air cathode catalyst. 

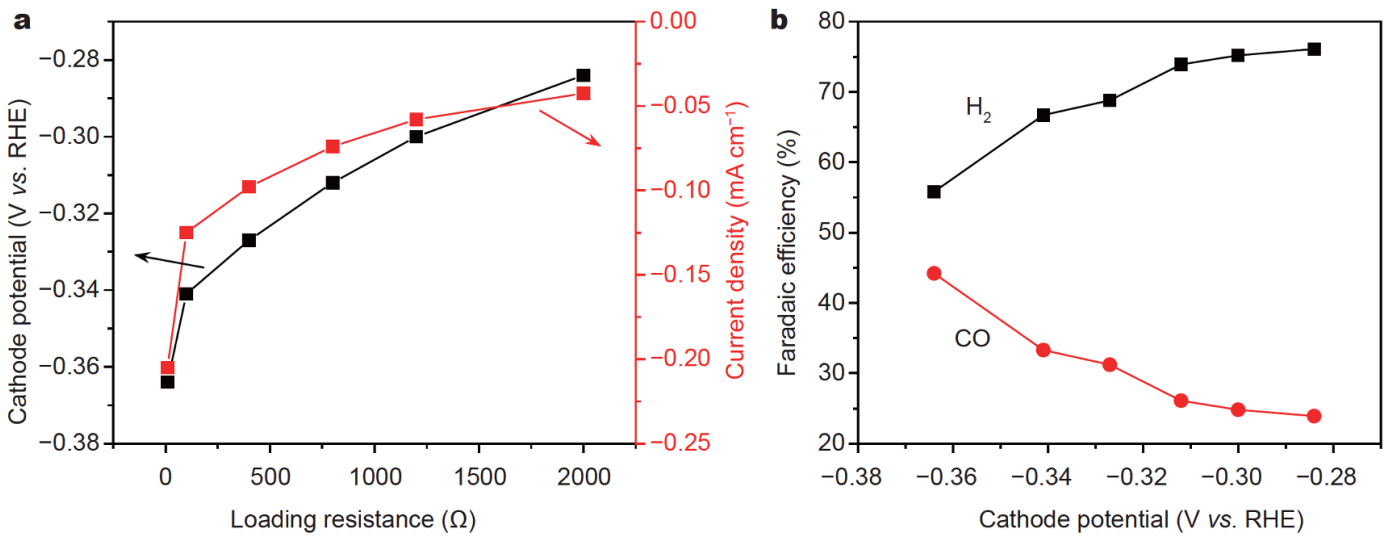

Figure 4 (a) Cathode potential and circuit current density of the MFC-MEC coupled system under different load resistances. (b) Faradaic efficiency of $\mathrm{CO}$ and $\mathrm{H}_{2}$ in the MFC-MEC coupling system at different cathode potentials.

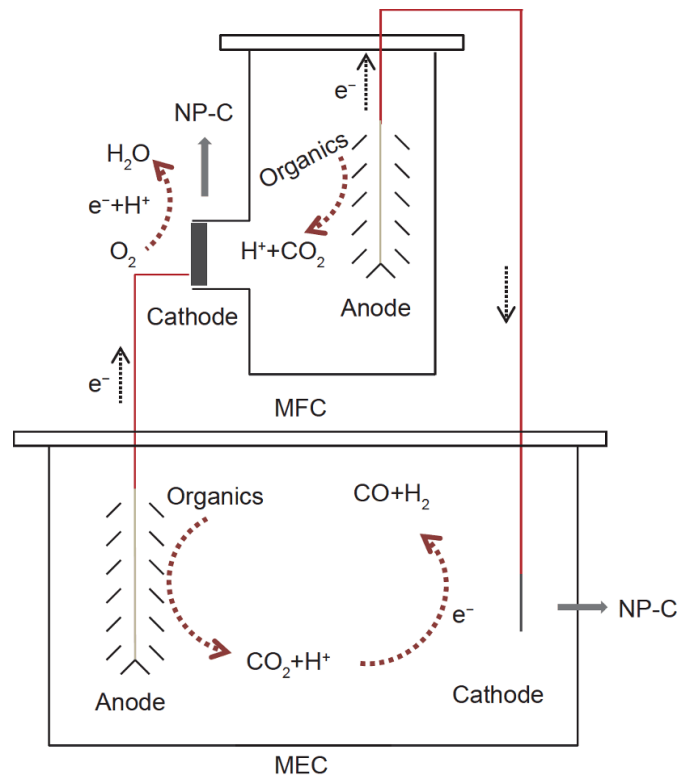

Figure 5 Conceptual diagram toward spontaneous production of syngas by electrochemical strategy in biogas digesters.

shown in Fig. 5.

\section{CONCLUSIONS}

In summary, we designed and prepared a biocompatible metal-free N/P-co-doped carbon catalyst via facile onepot pyrolysis of cellulose mixed with urea and phytic acid. The NP-C is an excellent bifunctional electrocatalyst for the CDRR/ORR. For the CDRR, the NP-C catalyst achieved $81 \% \mathrm{FE}_{\mathrm{CO}}$ at $-0.59 \mathrm{~V} v$ s. RHE, while in the ORR, its performance (initial potential of $0.84 \mathrm{~V}$ ) was comparable to commercial $20 \% \mathrm{Pt} / \mathrm{C}$ (initial potential of
$0.85 \mathrm{~V}$ ) under the neutral condition. Meanwhile, when NP-C was used as the air cathode, the MFC can generate an open circuit voltage of $790 \mathrm{mV}$ and a maximum power density of $2021 \mathrm{~mW} \mathrm{~m}^{-2}$. Based on the MFC-MEC coupling system, the NP-C exhibits excellent performance in the production of syngas without external power supply. When the load resistance was $10 \Omega$, the current density at the cathode of the MEC reached $-0.52 \mathrm{~mA} \mathrm{~cm}^{-2}$, and the FEs of $\mathrm{CO}$ and $\mathrm{H}_{2}$ were $60 \%$ and $40 \%$, respectively. By adjusting the load resistance, the $\mathrm{CO} / \mathrm{H}_{2}$ ratio was suitable for the typical range of syngas ratios $\left(\mathrm{CO} / \mathrm{H}_{2}, 0.23-2.26\right)$ in a typical thermal catalytic reaction.

\section{Received 26 May 2020; accepted 30 July 2020;}

published online 19 October 2020

1 McNeil BI, Sasse TP. Future ocean hypercapnia driven by anthropogenic amplification of the natural $\mathrm{CO}_{2}$ cycle. Nature, 2016, 529: 383-386

2 Zhu DD, Liu JL, Qiao SZ. Recent advances in inorganic heterogeneous electrocatalysts for reduction of carbon dioxide. Adv Mater, 2016, 28: 3423-3452

3 Qiao J, Liu Y, Hong F, et al. A review of catalysts for the electroreduction of carbon dioxide to produce low-carbon fuels. Chem Soc Rev, 2014, 43: 631-675

4 Wender I. Reactions of synthesis gas. Fuel Proc Tech, 1996, 48: 189-297

5 Cao Y, Gao Z, Jin J, et al. Synthesis gas production with an adjustable $\mathrm{H}_{2} / \mathrm{CO}$ ratio through the coal gasification process: effects of coal ranks and methane addition. Energy Fuels, 2008, 22: 17201730

6 Mistry H, Reske R, Zeng Z, et al. Exceptional size-dependent activity enhancement in the electroreduction of $\mathrm{CO}_{2}$ over $\mathrm{Au}$ nanoparticles. J Am Chem Soc, 2014, 136: 16473-16476

7 Kang P, Chen Z, Nayak A, et al. Single catalyst electrocatalytic reduction of $\mathrm{CO}_{2}$ in water to $\mathrm{H}_{2}+\mathrm{CO}$ syngas mixtures with water oxidation to $\mathrm{O}_{2}$. Energy Environ Sci, 2014, 7: 4007-4012

8 Ghausi MA, Xie J, Li Q, et al. $\mathrm{CO}_{2}$ overall splitting by a bifunc- 
tional metal-free electrocatalyst. Angew Chem Int Ed, 2018, 57: 13135-13139

9 Dubrawski KL, Shao X, Milton RD, et al. Microbial battery powered enzymatic electrosynthesis for carbon capture and generation of hydrogen and formate from dilute organics. ACS Energy Lett, 2019, 4: 2929-2936

10 Sun M, Sheng GP, Mu ZX, et al. Manipulating the hydrogen production from acetate in a microbial electrolysis cell-microbial fuel cell-coupled system. J Power Sources, 2009, 191: 338-343

11 Li Y, Yang HY, Shen JY, et al. Enhancement of azo dye decolourization in a MFC-MEC coupled system. Bioresource Tech, 2016, 202: 93-100

12 Li M, Pan Y, Huang L, et al. Continuous flow operation with appropriately adjusting composites in influent for recovery of $\mathrm{Cr}(\mathrm{VI}), \mathrm{Cu}(\mathrm{II})$ and $\mathrm{Cd}(\mathrm{II})$ in self-driven MFC-MEC system. Environ Tech, 2017, 38: 615-628

13 Zhao $\mathrm{H}$, Zhang $\mathrm{Y}$, Zhao B, et al. Electrochemical reduction of carbon dioxide in an MFC-MEC system with a layer-by-layer selfassembly carbon nanotube/cobalt phthalocyanine modified electrode. Environ Sci Technol, 2012, 46: 5198-5204

14 Liu X, Dai L. Carbon-based metal-free catalysts. Nat Rev Mater, 2016, 1: 16064

15 Dai L, Xue Y, Qu L, et al. Metal-free catalysts for oxygen reduction reaction. Chem Rev, 2015, 115: 4823-4892

16 Wang X, Sun G, Routh P, et al. Heteroatom-doped graphene materials: syntheses, properties and applications. Chem Soc Rev, 2014, 43: 7067-7098

17 Wu J, Liu M, Sharma PP, et al. Incorporation of nitrogen defects for efficient reduction of $\mathrm{CO}_{2}$ via two-electron pathway on threedimensional graphene foam. Nano Lett, 2016, 16: 466-470

18 Song Y, Chen W, Zhao C, et al. Metal-free nitrogen-doped mesoporous carbon for electroreduction of $\mathrm{CO}_{2}$ to ethanol. Angew Chem Int Ed, 2017, 56: 10840-10844

19 Liu Y, Chen S, Quan X, et al. Efficient electrochemical reduction of carbon dioxide to acetate on nitrogen-doped nanodiamond. J Am Chem Soc, 2015, 137: 11631-11636

20 Kumar B, Asadi M, Pisasale D, et al. Renewable and metal-free carbon nanofibre catalysts for carbon dioxide reduction. Nat Commun, 2013, 4: 2819

21 Sharma PP, Wu J, Yadav RM, et al. Nitrogen-doped carbon nanotube arrays for high-efficiency electrochemical reduction of $\mathrm{CO}_{2}$ : On the understanding of defects, defect density, and selectivity. Angew Chem Int Ed, 2015, 54: 13701-13705

22 Xie J, Zhao X, Wu M, et al. Metal-free fluorine-doped carbon electrocatalyst for $\mathrm{CO}_{2}$ reduction outcompeting hydrogen evolution. Angew Chem, 2018, 130: 9788-9792

23 Yang $\mathrm{H}, \mathrm{Wu} \mathrm{Y}$, Lin $\mathrm{Q}$, et al. Composition tailoring via $\mathrm{N}$ and $\mathrm{S}$ codoping and structure tuning by constructing hierarchical pores: metal-free catalysts for high-performance electrochemical reduction of $\mathrm{CO}_{2}$. Angew Chem, 2018, 130: 15702-15706

24 Logan BE, Hamelers B, Rozendal R, et al. Microbial fuel cells: methodology and technology. Environ Sci Technol, 2006, 40: 5181-5192

25 Harnisch F, Schröder U. From MFC to MXC: chemical and biological cathodes and their potential for microbial bioelectrochemical systems. Chem Soc Rev, 2010, 39: 4433-4448

26 HaoYu E, Cheng S, Scott K, et al. Microbial fuel cell performance with non-Pt cathode catalysts. J Power Sources, 2007, 171: 275-281

27 Morris JM, Jin S, Wang J, et al. Lead dioxide as an alternative catalyst to platinum in microbial fuel cells. Electrochem Commun,
2007, 9: 1730-1734

28 Feng L, Yan Y, Chen Y, et al. Nitrogen-doped carbon nanotubes as efficient and durable metal-free cathodic catalysts for oxygen reduction in microbial fuel cells. Energy Environ Sci, 2011, 4: 18921899

29 Gong K, Du F, Xia Z, et al. Nitrogen-doped carbon nanotube arrays with high electrocatalytic activity for oxygen reduction. Science, 2009, 323: 760-764

30 Cong HP, Wang P, Gong M, et al. Facile synthesis of mesoporous nitrogen-doped graphene: An efficient methanol-tolerant cathodic catalyst for oxygen reduction reaction. Nano Energy, 2014, 3: 5563

31 Lai L, Potts JR, Zhan D, et al. Exploration of the active center structure of nitrogen-doped graphene-based catalysts for oxygen reduction reaction. Energy Environ Sci, 2012, 5: 7936-7942

32 Nakajima T, Koh M, Gupta V, et al. Electrochemical behavior of graphite highly fluorinated by high oxidation state complex fluorides and elemental fluorine. Electrochim Acta, 2000, 45: 16551661

33 Zheng Y, Jiao Y, Chen J, et al. Nanoporous graphitic- $\mathrm{C}_{3} \mathrm{~N}_{4} @$ carbon metal-free electrocatalysts for highly efficient oxygen reduction. J Am Chem Soc, 2011, 133: 20116-20119

34 Zhang F, Cheng S, Pant D, et al. Power generation using an activated carbon and metal mesh cathode in a microbial fuel cell. Electrochem Commun, 2019, 11: 2177-2179

35 Watson VJ, Delgado CN, Logan BE. Influence of chemical and physical properties of activated carbon powders on oxygen reduction and microbial fuel cell performance. Environ Sci Technol, 2013, 47: 6704-6710

$36 \mathrm{Hu} \mathrm{X}, \mathrm{Wu} \mathrm{Y}, \mathrm{Li} \mathrm{H}$, et al. Adsorption and activation of $\mathrm{O}_{2}$ on nitrogen-doped carbon nanotubes. J Phys Chem C, 2010, 114: 9603-9607

37 Liu Q, Chen S, Zhou Y, et al. Phosphorus-doped carbon derived from cellulose phosphate as efficient catalyst for air-cathode in microbial fuel cells. J Power Sources, 2014, 261: 245-248

38 Liu ZW, Peng F, Wang HJ, et al. Phosphorus-doped graphite layers with high electrocatalytic activity for the $\mathrm{O}_{2}$ reduction in an alkaline medium. Angew Chem Int Ed, 2011, 50: 3257-3261

39 Wang S, Iyyamperumal E, Roy A, et al. Vertically aligned BCN nanotubes as efficient metal-free electrocatalysts for the oxygen reduction reaction: a synergetic effect by co-doping with boron and nitrogen. Angew Chem Int Ed, 2011, 50: 11756-11760

40 Wu J, Sharifi T, Gao Y, et al. Emerging carbon-based heterogeneous catalysts for electrochemical reduction of carbon dioxide into value-added chemicals. Adv Mater, 2019, 31: 1804257

41 Yang $\mathrm{H}, \mathrm{Wu} \mathrm{Y}$, Lin $\mathrm{Q}$, et al. Composition tailoring via $\mathrm{N}$ and $\mathrm{S}$ codoping and structure tuning by constructing hierarchical pores: metal-free catalysts for high-performance electrochemical reduction of $\mathrm{CO}_{2}$. Angew Chem Int Ed, 2018, 57: 15476-15480

42 Chen $\mathrm{C}$, Sun $\mathrm{X}$, Yan X, et al. Boosting $\mathrm{CO}_{2}$ electroreduction on $\mathrm{N}$, P-co-doped carbon aerogels. Angew Chem Int Ed, 2020, 59: 11123-11129

43 Zhu Y, Lv K, Wang X, et al. 1D/2D nitrogen-doped carbon nanorod arrays/ultrathin carbon nanosheets: outstanding catalysts for the highly efficient electroreduction of $\mathrm{CO}_{2}$ to $\mathrm{CO}$. J Mater Chem A, 2019, 7: 14895-14903

44 Singh SK, Takeyasu K, Nakamura J. Active sites and mechanism of oxygen reduction reaction electrocatalysis on nitrogen-doped carbon materials. Adv Mater, 2019, 31: 1804297

45 Yang L, Shui J, Du L, et al. Carbon-based metal-free ORR elec- 
trocatalysts for fuel cells: past, present, and future. Adv Mater, 2019, 31: 1804799

46 Li R, Wei Z, Gou X. Nitrogen and phosphorus dual-doped graphene/carbon nanosheets as bifunctional electrocatalysts for oxygen reduction and evolution. ACS Catal, 2015, 5: 4133-4142

Acknowledgements This work was supported by the National Natural Science Foundation of China (21872147 and 21805277), the Natural Science Foundation of Fujian Province (2018J05030 and 2019J05152), the Key Research Program of Frontier Sciences, CAS (ZDBS-LYSLH028), DNL Cooperation Fund, CAS (DNL201924), and the Strategic Priority Research Program, CAS (XDB20000000).

Author contributions Wang Y designed the experiments; Wang W performed the experiments; Wang $\mathrm{W}$ wrote the paper with support from Borse RA and Xie J. All authors contributed to the general discussion.

Conflict of interest The authors declare no conflict of interest.

Supplementary information online version of the paper.

Supporting data are available in the

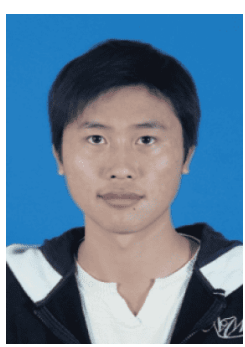

Wei Wang is currently a $\mathrm{PhD}$ student at Fujian Institute of Research on the Structure of Matter, Chinese Academy of Sciences. His research focuses on the syntheses of metal-free materials and their application in energy conversion and storage, especially for carbon dioxide reduction reactions.

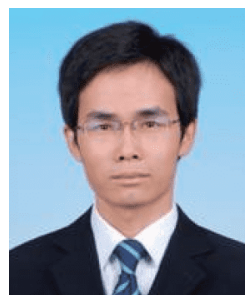

Yaobing Wang is a professor at Fujian Institute of Research on the Structure of Matter, Chinese Academy of Sciences. He received his $\mathrm{PhD}$ from the Institute of Chemistry, Chinese Academy of Sciences. His current research is focused on the syntheses of novel 2D materials and their application in energy conversion and storage.

\section{基于生物相容性双功能无金属电催化剂的MFC- MEC耦合系统自发产生合成气}

$$
\text { 王玮 }{ }^{1,2} \text {, Rahul Anil Borse }{ }^{1,2} \text {, 谢佳芳 }{ }^{1} \text {, 王要兵 }{ }^{1,3^{*}}
$$

摘要 通过二氧化碳的电化学还原来制备高价值的燃料和化学品 对二氧化碳的良性循环具有重要意义. 然而, 由于二氧化碳电化学 还原过程中的高过电势, 导致驱动该还原反应需要高功耗和高成 本贵金属催化剂. 在本文中, 电化学二氧化碳还原反应是在微生物 燃料电池-微生物电解池(MFC-MEC) 耦合系统中具有生物相容性 的无金属氮磷共掺杂碳基材料上实现的. 基于MFC中的生物电化 学提供能量以驱动MEC中的电催化作用, 无需任何外部能量输入, 就可以从该耦合体系中自发产生合成气. 在MFC-MEC耦合体系 中, 对于二氧化碳还原反应和氧还原反应, NP-C材料是一种优良 的双功能电催化剂. 当负载电阻为 $10 \Omega$ 时, MEC阴极的电流密度可 达 $-0.52 \mathrm{~mA} \mathrm{~cm}^{-2}, \mathrm{CO}$ 和 $\mathrm{H}_{2}$ 的法拉第效率分别为 $60 \%$ 和 $40 \%$. 此外, 可以通过调节负载电阻来改变 $\mathrm{CO} / \mathrm{H}_{2}$ 产物比, 可满足进一步反应中 对于合成气使用的各种需求. 这项工作为通过沼气池中的微生物 系统自发生产合成气提供了一种新的电化学策略. 